\title{
Effects of repeated doses of scopolamine on the
}

\section{electroencephalographic stages of sleep in normal volunteers}

\begin{abstract}
Single doses of scopolamine markedly alter sleep patterns in man. This study intended to evaluate the persistence of these changes during continued administration. The design consisted of a sequence of habituation, no-medication, suiline (control), scopolamine $(0.006 \mathrm{mg} / \mathrm{kg}$ intramuscularly 3 consecutive nights), and saline. The first dose of scopolamine markedly retarded the onset of stage rapid eye movement (REM) sleep $(p<0.005)$ and diminished the total amount of REM sleep during the night $(p<0.025)$. $A$ decrease in total number of eye movements $(p<0.05)$ and an increase in body movements $(p<0.025)$ were also observed. Changes after the second dose of scopolamine were less marked but still significant. The third dose of scopolamine produced less marked changes than the preceding two. When compared with the first scopolamine night, the onset of stage REM was retarded to a lesser extent $(p<0.05)$ and the total amount of REM sleep was increased $(p<0.05)$. An increase in the duration of the first REM period was also observed. Rebound effects on the appearance of the first REM period $(p<0.01)$, number of eye movements $(p<0.001)$, total amount of REM sleep $(p<0.01)$, and body movements were observed in the last saline night.
\end{abstract}

T. Sagalés, M.D., S. Erill, M.D., and E. F. Domino, M.D. Ann Arbor, Mich., and Barcelona, Spain Department of Pharmacology, University of Michigan, and Departamento de Farmacología y Terapéutica Universidad Autónoma de Barcelona

The modification of the normal electroencephalographic (EEG) patterns of sleep by a variety of drugs is well documented. It has been the subject of several comprehensive reviews. ${ }^{9}$. ${ }^{11}$ Drugs affecting the EEG stages of sleep in man include various categories of centrally

Supported in part by Grant No. MY-02653, United States Public Health Service.

Presented as an oral communication at the Sixth International Congress of Pharmacology. July 21, 1975, Helsinki, Finland.

Received for publication Aug. 30, 1975.

Accepted for publication Sept. 11. 1975.

Reprint requests to: Dr. E. F. Domino, 6440 Medical Science Building I, Department of Pharmacology, University of Michigan Ann Arbor, Mich. 48104. acting agents and, notably, substances with marked activity on central cholinergic ${ }^{7,} 18$ and serotonergic $^{5,21}$ pathways. One aspect that has received some attention is the possible development of tolerance toward the drug-induced alteration of the sleep stages on continuing administration, and the appearance of rebound effects on withdrawal. Reports concerning tolerance and withdrawal effects have been scarce and in some cases of a rather anecdotal character. The existence of these effects has been challenged in the case of barbiturates, ${ }^{6} \mathrm{a}$ series of drugs for which tolerance and withdrawal phenomena had been claimed. ${ }^{8,} 14$ 

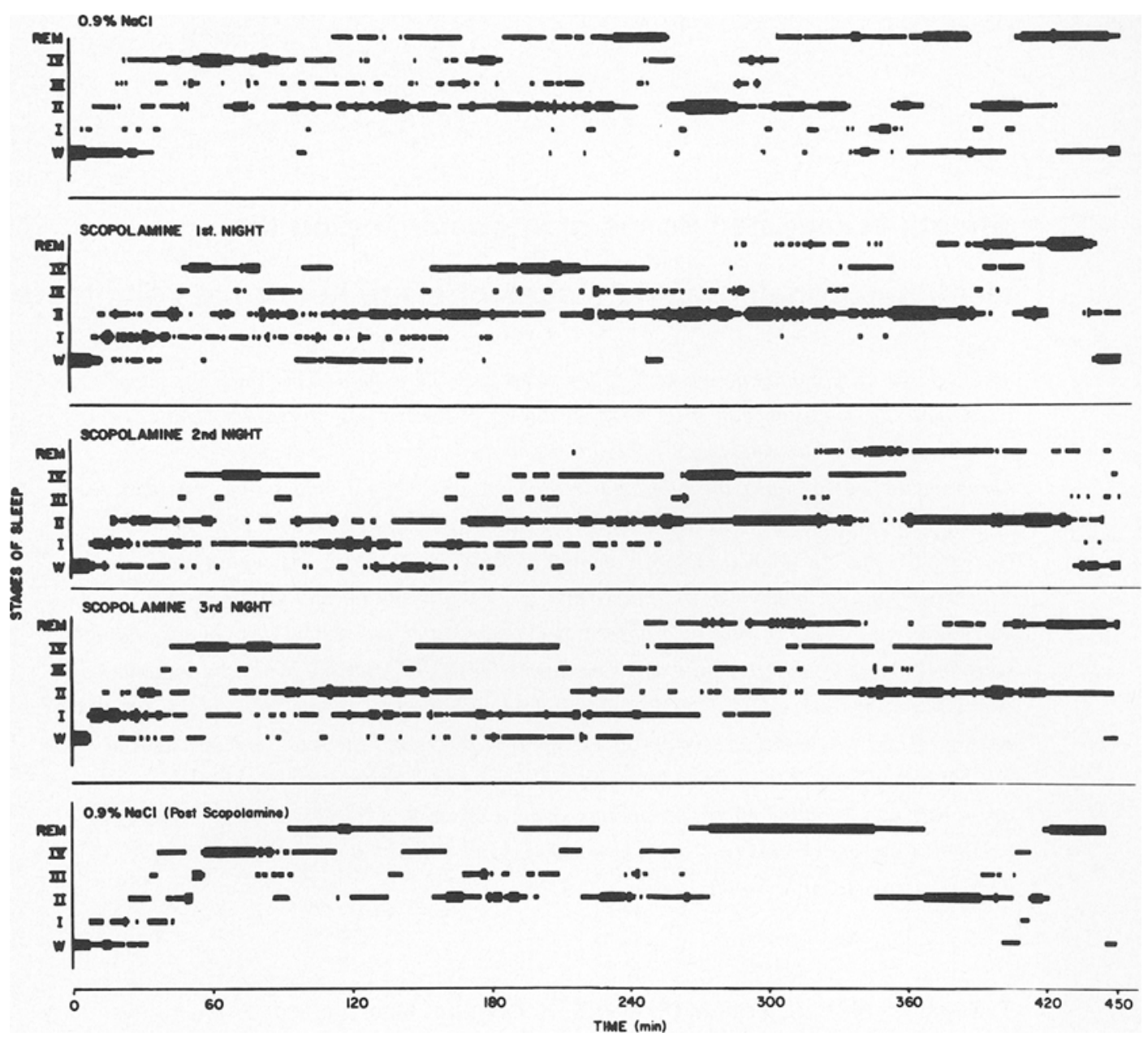

Fig. 1. Effects of nightly scopolamine on the distribution of the stages of sleep in humans. Each stage of sleep for each min of 3 volunteers is represented in block format. The mean stages of sleep are represented as the thickness of the block and its duration by its length. Note that scopolamine decreased the per cent of REM sleep and prolonged the time to first REM. With each subsequent dose the effect was less (tolerance), and following the last injection (saline) a REM rebound was observed.

This study was undertaken to explore whether tolerance to the effects on the EEG patterns of sleep developed after successive doses of scopolamine, a drug with clear-cut central effects, and whether any rebound was apparent upon interruption of the treatment.

\section{Methods}

Three healthy young males 21,23 , and 25 years of age participated in the experiment after a complete history and physical examination had been obtained. Well-organized alpha rhythm in the occipital areas during a resting
EEG was present in all cases. The participants were instructed to abstain from alcohol or any other pharmacologically active substance other than coffee or tobacco during the study and in the $24 \mathrm{hr}$ prior to its beginning. Coffee or tobacco was not permitted after 7 P.M. The recordings were made in a sound-attenuated, temperature-controlled room. The first night of the study was used for habituation; electrodes for polygraphic recordings were placed but a continuous all-night recording was not obtained, although this was not known by the participants. After this night a sequence of $0.9 \%$ 
Table I. Effects of saline and scopolamine on stages of sleep in man

\begin{tabular}{l|r|r|r|r|c|c}
\hline \multirow{2}{*}{ Drug } & \multicolumn{7}{c}{ Stages of sleep (mean per cent $\pm S E$ ) } \\
\cline { 2 - 8 } & $W$ & $I$ & $I I$ & $I I I$ & $I V$ & $R E M$ \\
\hline Saline & $12.7 \pm 6.0$ & $3.8 \pm 1.7$ & $35.7 \pm 6.5$ & $10.2 \pm 1.5$ & $15.9 \pm 1.4$ & $23.7 \pm 2.9$ \\
$\begin{array}{l}\text { Scopolamine, } \\
\text { first dose }\end{array}$ & $9.5 \pm 5.1$ & $10.2 \pm 4.1$ & $46.5 \pm 6.0$ & $6.2 \pm 0.3$ & $17.1 \pm 2.1$ & $10.2 \pm 1.4^{*}$ \\
$\begin{array}{l}\text { Scopolamine, } \\
\text { second dose }\end{array}$ & $11.1 \pm 2.8$ & $17.8 \pm 10.0$ & $41.3 \pm 10.7$ & $3.7 \pm 0.9 \dagger$ & $18.1 \pm 1.3$ & $7.9 \pm 1.1 \dagger$ \\
$\begin{array}{l}\text { Scopolamine, } \\
\text { third dose }\end{array}$ & $9.1 \pm 4.4$ & $21.9 \pm 8.8$ & $30.1 \pm 3.9$ & $5.5 \pm 1.9$ & $18.5 \pm 0.5$ & $15.4 \pm 1.2$ \\
Saline & $5.9 \pm 0.1$ & $3.2 \pm 2.8$ & $29.7 \pm 4.1$ & $8.5 \pm 1.0$ & $15.8 \pm 2.6$ & $36.9 \pm 3.1 \dagger$ \\
\hline
\end{tabular}

Difference from first saline night: $* \mathrm{p}<0.025 ; \uparrow \mathrm{p}<0.001$.

W: awake.

$\mathrm{NaCl}$ (saline), scopolamine $(0.4 \mathrm{mg})$ for 3 consecutive nights, and saline followed in each case. Injections were given low in the deltoid muscle and the volume was $1.2 \mathrm{ml}$ in all cases. The sequence used was not known either by the subjects or by the technician monitoring the all-night recording. Subjects entered the sleep laboratory at 9:45 P.M., and application of the polygraph electrodes was begun immediately. In all cases a calibration record was made before 11:00 P.M., and at this time the scheduled injection was given in accordance with the above-described experimental design. Lights in the sound-attenuated chamber were turned off after the drug administration, and a continuous polygraph recording was begun. During all recording periods the room temperature was kept at a comfortable level, according to individual subject preferences, and every effort was made to achieve a comfortable and as natural as possible environment for each individual. An intercom was available for two-way communication. At 6:30 A.M. the subjects were awakened and the recording interrupted.

At the beginning of each recording night, silver disc scalp electrodes were placed at positions $\mathrm{F}_{3}, \mathrm{C}_{3}, \mathrm{C}_{4}, \mathrm{P}_{3}$, and $\mathrm{O}_{1}$ as defined by the 10-20 International System. Beckman selfadhesive electrodes placed at $\mathrm{F}_{\mathrm{pl}}$, the outer canthi of both eyes, and submentally. These served as ground, electrooculogram (EOG), and electromyogram (EMG), respectively. Two Telectrode self-adhesive electrodes placed on the lobule of each ear and connected together served as reference. EEG, EMG, and EOG were recorded on an 8-channel Grass polygraph placed outside the sleeping chamber. Paper speed was $15 \mathrm{~mm}$ per second and a calibration of $50 \mu \mathrm{V}$ per centimeter was used in the EEG channels. The calibration of the EMG recording was $10 \mu \mathrm{V}$ per centimeter and that of the EOG was $100 \mu \mathrm{V}$ per centimeter.

All sleep records were coded and scored without knowledge of the treatment given in each case. Modified criteria of Dement and Kleitman ${ }^{4}$ and Williams, Agnew, and Webb ${ }^{20}$ were used for scoring as described in a previous publication. ${ }^{18}$

\section{Results}

The overall pattern of sleep of the participant subjects in the 5 consecutive nights is presented in Fig. 1. The $x$ axis represents the number of subjects in a given stage of sleep; 1 small square represents 1 subject. Quantitative data for each stage of sleep are given in Tables I to III. The first dose of scopolamine markedly retarded the onset of REM sleep (from $126.0 \pm 8.4 \mathrm{~min}$ in the initial, i.e., control saline night, to $301.2 \pm 9.0 \mathrm{~min}, \mathrm{p}<$ 0.005 ) and diminished the total amount of REM sleep during the night (from a mean per cent of $23.7 \pm 2.9$ to $10.2 \pm 1.4, p<0.025$ )

The total number of episodes of REM was reduced (from $4.0 \pm 0.6$ to $2.0 \pm 0.6$ ) and a decrease in the total number of eye movements $(p<0.025)$ was also observed. The duration of the first REM period was not affected.

Changes induced by the second dose of scopolamine were similar and also significant when compared with the control night. However, 
Table II. Effects of saline and scopolamine on mean per cent of NREM, REM,BM, and number of eye movements

\begin{tabular}{l|c|c|c|c|c}
\hline \multicolumn{1}{c|}{ Drug } & N & NREM & REM & BM & $\begin{array}{c}\text { Total number of } \\
\text { rapid eye } \\
\text { movements }\end{array}$ \\
\hline Saline & 3 & $72.4 \pm 5.6$ & $23.7 \pm 2.9$ & $0.2 \pm 0.2$ & $681.6 \pm 152.6$ \\
Scopolamine, first dose & 3 & $80.2 \pm 5.1$ & $10.1 \pm 1.4^{*}$ & $5.0 \pm 1.2^{*}$ & $242.0 \pm 36.3^{*}$ \\
Scopolamine, second dose & 3 & $79.4 \pm 1.5$ & $7.9 \pm 1.1 \dagger$ & $5.3 \pm 0.8 \ddagger$ & $309.3 \pm 49.9$ \\
Scopolamine, third dose & 3 & $75.5 \pm 5.5$ & $15.4 \pm 1.39$ & $3.9 \pm 0.9$ & $365.6 \pm 94.1 \S$ \\
Saline & 2 & $57.2 \pm 3.2$ & $36.9 \pm 3.1 \dagger$ & $0 \pm 0$ & $1773.5 \pm 82.0 \ddagger$ \\
\hline
\end{tabular}

Difference from first saline night: ${ }^{*} \mathrm{p}<0.025 ; \ddagger \mathrm{p}<0.001 ; \mathrm{p}<0.005 ; \mathrm{p}<0.05$.

Difference from first scopolamine night: $\uparrow \mathrm{p}<0.005$

$\mathrm{N}$ : number of subjects.

NREM: non-REM

REM: rapid eye movements.

BM: body movements

Table III. Effects of saline and scopolamine on number of episodes of REM, REM latency, duration of the first REM period, and REM minutes by thirds of night in the sleep of man

\begin{tabular}{|c|c|c|c|c|c|c|}
\hline \multirow[b]{2}{*}{ Drug } & \multirow{2}{*}{$\begin{array}{l}\text { Number of } \\
\text { REM } \\
\text { episodes }\end{array}$} & \multirow{2}{*}{$\begin{array}{c}R E M \\
\text { latency }\end{array}$} & \multirow{2}{*}{$\begin{array}{c}\text { Duration of } \\
\text { first } R E M \text { period }\end{array}$} & \multicolumn{3}{|c|}{$R E M$ minutes by thirds of night } \\
\hline & & & & First & Second & Third \\
\hline Sali & 0.6 & $126.0 \pm 8.4$ & $15.0 \pm 5.5$ & $8.7 \pm 0.7$ & $36.0 \pm 2.9$ & $62.0 \pm 11.0$ \\
\hline $\begin{array}{l}\text { Scopolamine, } \\
\text { first dose }\end{array}$ & $2.0 \pm 0.6$ & $301.2 \pm 9.0^{*}$ & $10.3 \pm 4.1 \dagger$ & 0 & 0 & $46.0 \pm 6.0$ \\
\hline $\begin{array}{l}\text { Scopolamine, } \\
\text { second dose }\end{array}$ & $1.6 \pm 0.3$ & $340.2 \pm 12.0^{*}$ & $30.3 \pm 7.7$ & 0 & 0 & $36.0 \pm 4.6$ \\
\hline $\begin{array}{l}\text { Scopolamine } \\
\text { third dose }\end{array}$ & $2.3 \pm 0.3 \dagger$ & $262.2 \pm 12.6 \ddagger$ & $37.0 \pm 10.9$ & 0 & $17.7 \pm 8.4$ & $51.3 \pm 7.0$ \\
\hline Saline & $3.5 \pm 0.5$ & $103.3 \pm 11.4 \dagger$ & $33.5 \pm 6.5 \dagger$ & $31.5 \pm 4.5$ & $50.5 \pm 11.5$ & $84.0 \pm 7.0$ \\
\hline
\end{tabular}

Difference from first saline night: ${ }^{*} p<0.005 ; \uparrow p<0.05$.

Difference from first scopolamine night: $\$ p<0.05$

an increase in the duration of the first REM period was observed. This increase was significant compared to the control night $(p<0.05)$. The third consecutive dose of scopolamine produced less marked changes than the preceding two, particularly with regard to total REM inhibition and REM latency $(p<0.05$ when compared with the first scopolamine night, in both cases). REM sleep was already detected during the second third of the night. The extended duration of the first REM period observed during the second scopolamine night was still present.

Administration of saline after 3 consecutive doses of scopolamine produced rebound effects on latency and amount of REM sleep ( $p<0.05$ and $p<0.01$, respectively). The increase in REM sleep was observed throughout the night but was particularly marked in the first third of it $(p<0.01$ when compared with the same period of the control night).

There were also rebound effects on total number of eye movements $(p<0.005)$. The duration of the first REM period was longer than in the control night $(\mathrm{p}<0.05)$, as it was in the preceding two nights.

\section{Discussion}

In recent years there have appeared several reports concerning the possible development of tolerance and rebound phenomena in the effects of drugs on the EEG patterns of sleep. ${ }^{1,8,10,14}$ Most of these studies dealt with the effects of barbiturates, and comparisons between successive daily doses in this category of drugs should be regarded with some 
caution. On one hand, the long half-life of most barbiturates ${ }^{19}$ would tend to account for quite different plasma levels on the consecutive nights and, on the other, the well-known enzyme-inducing properties of the long-acting members of this class ${ }^{16}$ may account also for important changes in their kinetics, although in an opposite way. The actual availability of successive doses is difficult to predict and may well vary according to the compound used or the size of the dose. Therefore, it is not surprising that results concerning effects of these drugs on the EEG sleep cycles in man have been conflicting. ${ }^{6,8}$ Tolerance and withdrawal effects have also been described following amphetamine and some of its derivatives, but the interpretation of these results is somewhat difficult since the available studies have dealt with addicts ${ }^{15}$ or lack enough data and statistical analysis. ${ }^{13}$

The results of our study confirm earlier findings on the acute effects of scopolamine on the EEG stages of sleep in $\operatorname{man}^{18}$ and contribute some evidence concerning the development of tolerance and rebound phenomena. It is interesting to note that the duration of the first REM period was already above the control values after the second dose of scopolamine and that this change persisted even after discontinuation of the treatment. Furthermore, there was distinct tolerance to the inhibition of the total amount of REM sleep and to the increase in REM latency with the third consecutive dose of scopolamine.

Rebound effects were also detected, both on REM latency and total amount of REM sleep. The shortening of REM latency, although small, was significant and was accompanied by a striking increase in the amount of REM stage in the first third of the night. Total amount of REM sleep was increased above control values and so was the total number of REMs. It has been suggested that REM sleep indicates increased protein synthesis in the brain and that REM sleep is a nonspecific indicator of many forms of synthesis in the brain. ${ }^{12}$ Our knowledge of the physiology of sleep is probably not sufficient to warrant acceptance or rejection of this hypothesis, but increased synthesis of transmitter following receptor blockade could perhaps be postulated to explain some cases of tolerance and withdrawal effects in sleep. Accumulation of acetylcholine in cholinergic nerve terminals has been demonstrated following blockade of its release in the guinea pig ileum, ${ }^{17}$ and increases in the synthesis of neurotransmitters very shortly after receptor blockade are well documented in the adrenergic and dopaminergic systems. ${ }^{2,3}$ We believe that our data, as well as those of other studies using different drugs with specific and clear-cut central effects, may help to elucidate the organization of sleep in man and the nature of its pharmacologic responsiveness.

\section{References}

1. Baekeland, F.: Pentobarbital and dextroamphetamine sulphate: Effects on the sleep cycle in man, Psychopharmacologia 11:388-396, 1967.

2. Berridge, T. L., and Sharman, D. F.: The effect of tranquilizing drugs on the concentration of the sulphate ester of 4-hydroxy-3methoxy-phenylethane-1-2-diol in rat brain, Br. J. Pharmacol. 51:156-158, 1974.

3. Carlsson, A., and Lindquist, M.: Effect of chlorpromazine or haloperidol on formation of 3 methoxytyramine and normetanephrine in mouse brain, Acta Pharmacol. Toxicol. 20: 140$144,1963$.

4. Dement, W., and Kleitman, N.: Cyclic variations in EEG during sleep and their relations to eye movements, body motility and dreaming, Electroencephalogr. Clin. Neurophysiol. 9:673$690,1957$.

5. Dunleavy, D. L. F., Brezinova, V., Oswald, I., MacLean, A. W., and Tinker, M.: Changes during weeks in effects of tricyclic drugs on the human sleeping brain, Br. J. Psychiatry 120:663-672, 1972.

6. Feinberg, I., Hibi, S., Cavness, C., and March, J.: Absence of REM rebound after barbiturate withdrawal, Science 185:534-535, 1974.

7. George, R., Haslett, W. L., and Jenden, D. J.: A cholinergic mechanism in the brainstem reticular formation: Induction of paradoxical sleep, Int. J. Neuropharmacol. 3:541-552, 1964.

8. Kales, A., Preston, T. A., Tan, T. L., and Allen, C.: Hypnotics and altered sleep-dream patterns, Arch. Gen. Psychiatry 23:211-218, 1970.

9. King, C. D.: The pharmacology of rapid eye movement sleep, Adv. Pharmacol. Chemother. 9:1-91, 1971 .

10. Lester, B. K., and Guerrero-Figueroa, R.: Effects of some drugs on electroencephalographic 
fast activity and dream time, Psychophysiology 2:224-236, 1966.

11. Oswald, I: Drugs and sleep, Pharmacol. Rev. 28:273-303, 1968.

12. Oswald, I.: Human brain proteins, drugs and dreams, Nature 223:893-897, 1969

13. Oswald, I., Jones, H. S., and Mannerheim, J. E.: Effects of two slimming drugs on sleep, Br. Med. J. 1:796-799, 1968.

14. Oswald, I., and Priest, R. G.: Five weeks to escape the sleeping pill habit, Br. Med. J. 4: 1903-1905, 1965.

15. Oswald, I., and Thacore, V. R.: Amphetamine and phenmetrazine addiction, Br. Med. J. 2: 427-431, 1963.

16. Remmer, $\mathrm{H}$. : Induction of drug metabolizing enzyme systems in the liver, Eur. J. Clin. Pharmacol. 5:116-136, 1972.

17. Richter, J. A., and Goldstein, A.: Effects of morphine and levorphanol on brain acetylcholine content in mice, J. Pharmacol. Exp. Ther. 175:685-691, 1970.
18. Sagalés, T., Erill, S., and Domino, E. F.: Differential effects of scopolamine and chlorpromazine on REM and NREM sleep in normal male subjects, Clin. Pharmacol. Ther. 10: $522-529,1969$.

19. Von Rossum, J. M.: Significance of pharmacokinetics for drug design and the planning of dosage regimens, in Ariens, E. J., editor: Drug design, New York, 1971, Academic Press, Inc., vol. 1, pp. 469-521.

20. Williams, R. L., Agnew, H. W., and Webb, W. B.: Sleep patterns in young adults: An EEG study, Electroencephalogr. Clin. Neurophysiol. 17:376-381, 1964.

21. Wyatt, R. J., Zarcone, V., Engelman, K., Dement, W. C., Snyder, F., and Sjoerdsma, A.: Effects of 5-hydroxytryptophan on the sleep of normal subjects, Electroencephalogr. Clin. Neurophysiol. 30:505-509, 1971. 